\section{Categorical results, categorical perception, and hindsight}

\section{DOMINIC W. MASSARO and JOSEPH M. HARY University of California, Santa Cruz, California}

Hindsight bias characterizes much of human action and is equally descriptive of scientific discovery. When Filippo Brunelleschi told the Overseers of the Works of the Florence Cathedral that he had a design for the Cupola of the Cathedral, they were reluctant to give him the commission until they saw the actual plans. (The Cathedral had been without a dome for years because of the difficulty of designing one to bridge without armature the great expanse between the walls.) Brunelleschi dissented, allowing that once seeing the plans, the Overseers would interpret his solution as obvious and thus not worthy of the commission. To illustrate his point, Brunelleschi challenged the Overseers to stand an egg on end. After hearing that one doesn't stand eggs on end, Brunelleshi gradually flattened the end of the egg on the table until it rested solidly on its end. Notwithstanding the predictable reply, "Anyone could have done it that way," Brunelleschi received the commission, and the Cathedral embraces his dome even today, five-and-a-half centuries later.

Hary and Massaro (1982) argued for maintaining a distinction between the phenomenon of categorical perception and the occurrence of categorical results in the identification/discrimination task. Although Pastore, Szczesiul, Wielgus, Nowikas, and Logan (1984) claim that this conclusion "has been reached by many researchers who have published over the last decade"' (p. 000), we ask why the study of categorical speech and nonspeech perception has been wedded to the identification/discrimination task? If categorical results in this task do not necessarily implicate categorical perception, how can they be diagnostic of the phenomenon or clarify the nature of the phenomenon? We now address each of the three criticisms given by Pastore et al.

\section{Categorical Perception Criteria}

The first specific criticism given by Pastore et al. (1984) is either incorrect or misguided. We are chided for failing to find chance performance within categories because, "with a $50 \%$ chance level, discrimination performance never was less than 60\%" (p. 000). However, given the unequal a priori probabilities, chance performance (if such a concept is meaningful)

The authors' mailing address is: Program in Experimental Psychology, University of California, Kerr Hall, Santa Cruz, CA 95064. is not $50 \%$ but probably closer to $60 \%$. Macmillan's (1983) reanalysis can be equally misleading, inasmuch as not all of the results were included in it, and the $d^{\prime}$ values depend on the particular model that is accepted for analysis.

Table 1 presents the discrimination probabilities for the standard and bipolar continua (Hary \& Massaro, 1982, Experiment 2). As can be seen by the hit and false-alarm probabilities, discrimination between same and different trials across the continuum depended on whether the continuum was standard or bipolar. Within the "pluck" category, performance was well above chance for short rise times on the standard continuum and very close to chance for the negative rise times on the bipolar continuum. Thus, there is absolutely no basis for the Pastore et al. (1984) claim that within-category performance in the bipolar continuum was significantly better than typical categorical perception results. The bottom line is that Figures 4 and 5 in the Hary and Massaro (1982) study, replotted as Figure 1 in Macmillan (1983), illustrate prototypical "noncategorical" and "categorical" results in the identification/discrimination task.

\section{Number of Continua}

Given an ordered set of stimuli, experts are free to debate how many physical continua are present. Pastore et al. (1984) go to great lengths to illustrate that our bipolar continuum was actually two continua. We are ambivalent about this analysis, but note that an equally valid argument could be made for the Pastore, Ahroon, Baffuto, Friedman, Puleo, and Fink (1977) experiment of identifying and discriminating loudness differences in the presence of a fixed background reference tone. In their situation, one continuum would represent tones that were louder than the reference tone, and the other would represent tones softer than the reference tone. The question of one or two continua matters not at all for our purposes because we understand that a linear change in an attribute of a physical stimulus does not necessarily mean that the psychological change should also be linear, logarithmic, or some other reasonable psychometric function. The psychophysical mapping between stimulus changes and perceptual changes is an independent issue and one not addressed in our criticism of the identification/discrimination task.

\section{Comparison With Earlier Theories}

One implication of the Pastore et al. (1984) paper is that our view is a restatement of, rather than an alternative to, earlier models of categorical perception. This is particularly difficult to understand because our theoretical framework has consistently 
Table 1

Observed Hit (Probability of Same Response Given Same Trial) and False Alarm (Probability of Same Response Given Different Trial) Probabilities as a Function of the Rise Time for the Standard and Bipolar Continua (Experiment 2, Hary and Massaro, 1982)

\begin{tabular}{|c|c|c|c|c|}
\hline \multirow[b]{3}{*}{ Rise Time } & \multicolumn{4}{|c|}{ Continuum } \\
\hline & \multicolumn{2}{|c|}{ Standard } & \multicolumn{2}{|c|}{ Bipolar } \\
\hline & Hit & False Alarm & Hit & False Alarm \\
\hline$-60,-30$ & & & .995 & .969 \\
\hline$-45,-15$ & & & .972 & $\begin{array}{l}.909 \\
.943\end{array}$ \\
\hline$-30, \quad 0$ & & & .945 & .674 \\
\hline$-15, \quad 15$ & & & .861 & .188 \\
\hline $0, \quad 30$ & .902 & .375 & .895 & .105 \\
\hline 15,45 & .833 & .442 & .861 & .560 \\
\hline $30, \quad 60$ & .801 & .488 & .942 & .910 \\
\hline $45, \quad 75$ & .782 & .550 & & \\
\hline $60, \quad 90$ & .854 & .801 & & \\
\hline 76,105 & .850 & .826 & & \\
\hline 90,120 & .924 & .889 & & \\
\hline
\end{tabular}

been one of continuous perception (Massaro \& Cohen, 1976, 1977, 1983a, 1983b, 1983c; Massaro \& Oden, 1980a, 1980b; Oden \& Massaro, 1978). As an example, Massaro and Cohen (1983b) contrasted categorical (discrete) and continuous models of bimodal speech perception and found that the predictions of the continuous model were over twice as accurate as those given by the categorical model. Massaro and Cohen (1983a) took great pains to analyze the distribution of rating responses to a given speech stimulus to test whether the listener had only categorical information or continuous information about the speech event. The results were more consistent with continuous than with categorical perception.

The strategy of much of the research since Cutting and Rosner's (1974) seminal study has followed the theme, "What occurs for speech can be demonstrated for nonspeech." Adopting the identification/ discrimination task used in speech research at Haskins Laboratories (Liberman, Harris, Hoffman, \& Griffith, 1957), the goal was to find nonspeech stimuli that gave results identical to those found with speech. However, as stressed by Massaro and Hary (1983), the identification/discrimination task is not diagnostic of the question of categorical versus continuous perception. The title of Hary and Massaro's paper was "Categorical results do not imply categorical perception." Thus, we believe that the derivative research enterprise using nonspeech in the identification/discrimination task is doomed to the same failure as the original research with speech.

\section{Conclusion}

We have always acknowledged previous research and conclusions arguing against the phenomenon of categorical perception (see Massaro, 1975, and Massaro \& Cohen, 1983a, for reviews). What Hary and Massaro's (1982) contribution provided was an explicit rejection of the diagnosticity of the identification/discrimination task for theories of categorical versus continuous perception.

\section{REFERENCES}

Cutting, J. E., \& Rosner, B. S. (1974). Categories and boundaries in speech and music. Perception \& Psychophysics, 16, 564-570.

Hary, J. M., \& Massaro, D. (1982). Categorical results do not imply categorical perception. Perception \& Psychophysics, 32, 409-418.

Liberman, A. M., Harris, K. S., Hoffman, H. S., \& GriffTh, B. C. (1957). The discrimination of speech sounds within and across phoneme boundaries. Journal of Experimental Psychology, 54, 358-368.

Macmillan, N. A. (1983). A psychophysical interpretation of a "categorical perception" experiment by Hary and Massaro. Perception \& Psychophysics, 34, 494-498.

MAssAro, D. W. (1975). Understanding language: An informationprocessing analysis of speech perception, reading, and psycholinguistics. New York: Academic Press.

Massaro, D. W., \& Cohen, M. M. (1976). The contribution of fundamental frequency and voice onset time to the $/ z \mathrm{i} /-/ \mathrm{si} /$ distinction. Journal of the Acoustical Society of America, 60, 704-717.

Massaro, D. W., \& Cohen, M. M. (1977). Voice-onset time and fundamental frequency as cues to the $/ \mathrm{zi} /-/ \mathrm{si} /$ distinction. Perception \& Psychophysics, 22, 373-382.

Massaro, D. W., \& Cohen, M. M. (1983a). Categorical or continuous speech perception: A new test. Speech Communication, 2, 15-35.

Massaro, D. W., \& Cohen, M. M. (1983b). Evaluation and integration of visual and auditory information in speech perception. Journal of Experimental Psychology: Human Perception and Performance, 9, 753-771.

Massaro, D. W., \& Cohen, M. M. (1983c). Phonological context in speech perception. Perception \& Psychophysics, 34, 338-348.

Massaro, D. W., \& Hary, J. M. (1983). Speech perception and psychophysics: Theory and experiment. Perception \& Psychophysics, 34, 499-502.

Massaro, D. W., \& Oden, G. C. (1980a). Evaluation and integration of acoustic features in speech perception. Journal of the Acoustical Society of America, 63, 81-97. 
Massaro, D. W., \& Oden, G. C. (1980b). Speech perception: A framework for research and theory. In N. J. Lass (Ed.), Speech and language: Advance in basic research and practice (Vol. 3). New York: Academic Press.

Oden, G. C., \& Massaro, D. W. (1978). Integration of featural information in speech perception. Psychological Review, 85, 172-191.

Pastore, R. E., Ahroon, W. A., Baffuto, K. J., Friedman, C., Puleo, J. S., \& Fink, E. A. (1977). Common-factor model of categorical perception. Journal of Experimental Psychology: Human Perception and Performance, 3, 686-696.

Pastore, R. E., Szczesiul, R., Wielgus, V., Nowikas, K., \& LogAn, R. (1984). Categorical perception, category boundary effects, and continuous perception: A reply to Hary and Massaro. Perception \& Psychophysics, 35, 583-585.

(Manuscript received April 10, 1984; accepted for publication April 10, 1984.) 